\title{
Functional unit and product functionality-addressing increase in consumption and demand for functionality in sustainability assessment with LCA
}

Kim, Seung Jin; Kara, Sami; Hauschild, Michael Zwicky

Published in:

International Journal of Life Cycle Assessment

Link to article, DOI:

10.1007/s11367-016-1233-3

Publication date:

2017

Document Version

Peer reviewed version

Link back to DTU Orbit

Citation (APA):

Kim, S. J., Kara, S., \& Hauschild, M. Z. (2017). Functional unit and product functionality-addressing increase in consumption and demand for functionality in sustainability assessment with LCA. International Journal of Life Cycle Assessment, 22(8), 1257-1265 . https://doi.org/10.1007/s11367-016-1233-3

\section{General rights}

Copyright and moral rights for the publications made accessible in the public portal are retained by the authors and/or other copyright owners and it is a condition of accessing publications that users recognise and abide by the legal requirements associated with these rights.

- Users may download and print one copy of any publication from the public portal for the purpose of private study or research.

- You may not further distribute the material or use it for any profit-making activity or commercial gain

- You may freely distribute the URL identifying the publication in the public portal 


\title{
Functional unit and product functionality - addressing increase in consumption and demand for functionality in sustainability assessment with LCA
}

\author{
Seung J in K im ${ }^{1}$, Sami K ara ${ }^{1}$, M ichael Hauschild ${ }^{2}$ \\ ${ }^{1}$ Sustainable M anufacturing and Life Cycle Engineering Group, School of M echanical \\ and $\mathrm{M}$ anufacturing Engineering, The University of $\mathrm{N}$ ew South $\mathrm{W}$ ales \\ ${ }^{2}$ D epartment of $M$ anagement Engineering, Division for Q uantitative Sustainability \\ A ssessment, Technical University of Denmark
}

Corresponding author: Seung J in Kim

Ph: +61-430 173357

Fax: +61-2-9663 1222

Email: seungjin.kim@unswalumni.com

\begin{abstract}
Purpose

The static functional unit definition in the current LCA framework has limitations in addressing the changing product functionality and associated environmental impact of constantly evolving product technologies. As a result, it overlooks the changes in consumer behaviour of increased consumption of products in provided services as well as in growing volumes. This article aims to present a new framework in defining a dynamic functional unit of product technologies that caters for changes in consumer behaviour and growing market.
\end{abstract}

\section{M ethods}

A new approach to defining the functional unit is proposed that caters for changes in consumer behaviour and the use of technology from a technical performance perspective. A dynamic approach to definition of the functional unit is proposed that is based on the K ano's model of product function and satisfaction.

\section{Results and Discussion}

The new approach is demonstrated on a case study in which the analysis of historical data for two TV product technologies - CRT and LCD - is used to show how the total environmental impact is increasing due to the increased functionality which triggers an increase in the volume of the market. Despite the efforts of improving product life cycle design, the society is still faced with increasing environmental impact from the product type overall.

\section{Conclusion}

This article presents the challenges of using a static, single functional unit definition in an industrial 
culture with constant evolution of products that influences usage behaviour and demonstrates the vicious circle of improving product efficiency that leads to further consumption and environmental impact. To address this problem, a new framew ork of dynamic functional unit definition is put forward for performing comparative LCA to manage the development of product life cycle design that helps keep the total environmental impact of the company's product portfolio within absolute boundaries.

Keywords: Functional unit; Comparative LCA ; Product technology; M arket volume; Sustainability 


\section{Introduction}

In a society faced with increasing levels of environmental impact, the assessment of environmental impact arising from human activity is important to guide efforts in reducing this impact towards sustainable levels. A Ithough many tools and methods are available to guide environmental assessment and improvements, research shows that overall environmental impact in society is on the rise - e.g. the atmospheric concentrations of man-made greenhouse gases are exponentially increasing with no indication of slowing down (IPCC 2007). Life Cycle A ssessment (LCA) is widely used to analyse and compare the environmental impacts of products or processes for a given functional unit. LCA guides the user through a systematic framework of goal definition, inventory analysis, classification, characterisation and valuation to quantify environmental impact scores for a broad range of environmental impacts and identify opportunities for improvement for an analysed product or service (ISO 2006). In the manufacturing industry, LCA is used to assess the influence of the manufacturing activities and their environmental impacts through use of raw material, production, usage and end-of-life involved in providing the products/services (Hauschild et al. 2005). In addition, comparative LCA is commonly performed to assess the environmental impact of new generations of products to identify if improvements have been achieved relative to the old generations of the products. For example, a comparative LCA of Cathode Ray Tube (CRT) vs. Liquid Crystal Display (LCD) TV was performed based on a common functional feature - the viewing size (Socolof et al. 2005). However, in this comparison there is a shift in the central technology applied in the product, and research has shown that different technologies may offer different levels and types of functionality and technology capacity (K im and K ara 2012). A case study of battery technology for electric vehicle application also demonstrated variance in environmental impact results when a different functional unit was chosen and this may be a source of uncertainty in some cases (M atheys et al. 2007). A s a rebound effect, technological development may thus influence the expectations and behaviour of consumers in the direction of demanding a higher level of performance or functionality - a change that may negatively offset any environmental improvements made in the new product (Sorell, 2009) so that the increased market volume and the associated consumption increase more than neutralises the efficiency gains, leading to the overall increase in environmental impact mentioned previously. Thus, applying the same functional unit with the assumption that two technologies offer the same kind of function/service may not be a true representation of actual consumer perception and behaviour. A nother important trend is the integration of several functionalities in a single product as a result of new technological developments. This leads to either unclear or overlapping boundaries in determining functional unit and scope when performing LCA and there could be discrepancies between the functionality and usage assumed by the manufacturer and the actual user behaviour of the consumer.

We identify a need to amend the current functional unit definition to ensure that these aspects of the product's life cycle - changes in functional requirement, environmental impact and market usage behaviour - are fully and correctly incorporated into LCA. This paper presents limitations of the current LCA framework in assessing multifunctional products and products that are or can be manufactured with different technologies (e.g. CRT or LCD) offering different levels of functionality. Building on these insights, an improved approach to functional unit definition will be presented, aiming to overcome such 
limitation by considering consumer/market behaviour building on input from the domain of product development.

\section{Method}

\subsection{Current LCA practice}

Current LCA practice is defined by the guideline set out in ISO14040 and the reference flow for which products are compared is based on the functional unit reflecting the customer's requirement to the product (ISO 2006). In a systematic process the standard stipulates the interconnected phases of goal definition, inventory analysis, classification, characterisation and valuation to quantify the environmental impact and identify possible improvement options.

For comparative LCA, products are assessed within consistent system boundaries defined in accordance with a common functional unit to identify which product performs better environmentally and identify areas for improvement. Comparative LCA is valid as long as the two products of interest offer the same functionality for the user. From this viewpoint, it is simple to assess and compare single-function products using a common functional unit and the current LCA framework. When the compared products have more than one function, and the additional functions differ, the LCA practitioner typically resorts to allocation or system expansion in order to focus on the primary function as defined in the functional unit. This procedure can be an important source of uncertainty in the comparative LCA .

\subsection{Limitations of current $L C A$ practice}

The problem arises as new product technologies enter the market and introduce the following types of changes:

- Improved performance of existing functions

- Influence of A dditional functions

o Fostering new functionalities that the consumer did not have access to before

o Integrating additional functionalities leading to possible sharing of common functions with unclear or overlapping system boundaries

- A Itered usage behaviour

\subsubsection{Improved performance of existing function: functionality and market behaviour}

It is a frequent strategy of manufacturers to provide improved functionality with the introduction of new technologies. For the TV case, it was observed that LCD offers higher level of functionality compared to CRT - assuming that the viewing size is the functionality expected by the consumer (CRT has a maximum size of 38 inches while LCD offered a size of 50 inches or greater at the time of the study, currently many TV s are offered in sizes exceeding 60 inches) (US EPA 2006). The problem however, is that as increased functionality is offered, consumers have the tendency to purchase higher performing 
products especially when they are offered at the same or lower price. This change in consumer behaviour is confirmed through market research that demonstrates that CRT had highest volume sales in the 19-20 inch category whereas LCD already years ago had highest volume sales in the 30-34 inch category (US EPA 2006). A lthough other factors such as changing standards of living and marketing of products will increase volume sales of the new product technology, it can be assumed that consumers will not purchase the new product unless it offers a genuine alternative with perceived improvements. Based on this assumption, the viewing size can be assumed to be the main functionality of concern for the consumer and changes in the market behaviour can be studied through the volume sold in each size category. This phenomenon can be understood in light of K ano's model of product quality that classifies product functions as basic features, performance features and excitement features ( $K$ ano 1984) as shown in Figure 1.

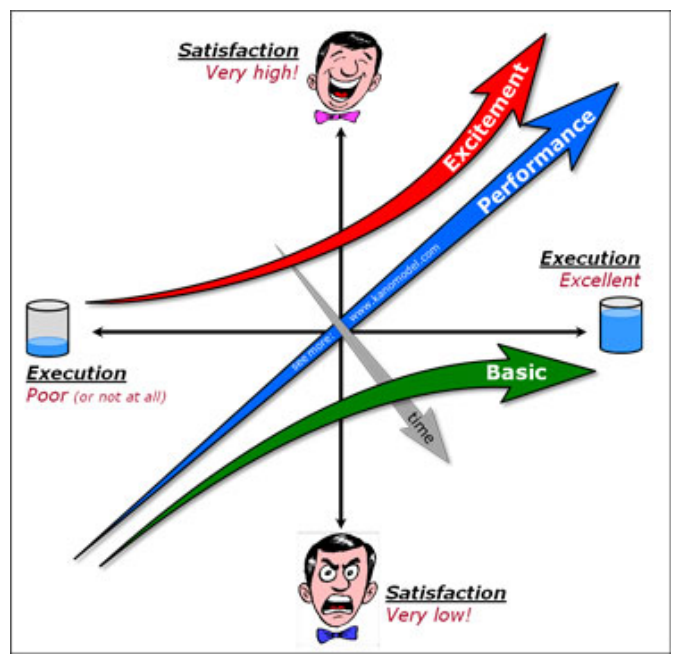

Fig. 1. The K ano M odel of product function and satisfaction (www.kanomodel.com)

Basic features comprise necessary functions that are assumed as essential by the consumer - if the product does not have these features it is not considered a valid offering by the consumer. P erformance features refer to the differing range of functionality offered by different products/technologies - these are the specifications on which the consumer will be comparing the competing alternatives. Excitement features refer to functionalities in a new product technology that offer possibilities to the consumer that were not previously possible. Thus, the level of customer satisfaction is dependent on how well the basic, performance and excitement features are executed by the manufacturer (Figure 1). As the figure shows, excitement features when executed well, leads to very high level of satisfaction and less so for performance features. The basic features at best reach neutral satisfaction and quickly lead to dissatisfaction if executed poorly demonstrating that to the customer these are perceived as essential. In the case of TV $s$, both CRT and LCD technologies offer the same basic features in terms of TV reception and video and sound display, but the performance feature screen size has increased as a result of the introduction of LCD technology. In addition, LCD offers an excitement feature with the slim screen profile that was not available with CRT technology. These features of the new products, as identified and categorised using K ano's model, can be used to determine the driver of the changing consumer behaviour and subsequently the definition of functional unit and the associated environmental impact. 


\subsubsection{Influence of additional functions}

In addition to improving existing functionality, a completely new function can be added as a result of technology development. The manufacture of the slim screen profiles that are unachievable with CRT technology, offers an example. The availability of this new function can become an excitement feature of the product even though it is not a necessity for the fundamental service offered by the product and over time, it is possible that consumers come to expect the new excitement features as part of the performance features of the product. A s illustrated in Figure 1, such a function may even become an expected basic feature of the product as described by K ano's model (K ano 1984). A $n$ eloquent example is offered by the development in mobile phones. Recently, the primary function of a mobile phone was to enable telephone calls while out of office or home. Through radical technology development, smartphones have been introduced that not only enable the wireless telephone function but also offer the function of a camera, computer with access to internet, music player and many other functions. A lthough it was not a necessity of a mobile phone to perform these functions when they were first introduced, the market began to adopt and expect such functions as basic features. In the case of LCD TVs, the slimmer screen profile was an excitement feature as it changed the way TV s are installed and used (such as hanging on walls) although it does not play any role in the primary function of video content display. In this perspective, the old technology of CRTs no longer offers a functional al ternative to many consumers due to the large physical depths limiting the possibilities of TV placement compared to LCDs.

W ith the integration of additional functionalities in the product, the system boundaries between the different functionalities often become unclear and overlapping due to their sharing of common product functions. Traditionally, printers, scanners and photocopiers were single-function, stand-alone products. As the printing and scanning mechanism could be shared with improved manufacturing technology, an integrated product that combines the three functions has been introduced.

From an LCA perspective, this can lead to unclear system boundaries between the functions and using a single functional unit definition may not accurately represent the actual product usage. For relatively simple products such as the integrated printer, scanner and photocopier, the analysis may not be too difficult but for complex products such as smartphones where integrated computing power is provided to enable many different functions (e.g. internet, camera, phone, music player etc.), determining the system boundary becomes vague and subject to interpretation which is a problem when comparisons are performed to functionally simpler products that offer only one or a few of the functions.

\subsubsection{Altered user behaviour - consumer vs. manufacturer}

A new or improved functionality may influence user behaviour and environmental impact and it is thus important to accurately model the consumer's actual usage of the product. Depending on how the functional unit is defined, varying environmental impact results could be observed (e.g. M atheys et al. 2007), and comparisons could come out differently. In comparing electronic media against traditional printed media, the assumed usage scenario played a vital role in determining the environmental impact - 
one type of media performed better than the other in one scenario but worse in another scenario. Thus, it is critical that the functional unit in a comparative LCA reflects the actual behaviour of the user and not the manufacturer's assumption about how the product is or will be used when the compared alternatives are not functionally equival ent (Hischier and Reichart 2003). Therefore, rather than al ways performing a comparative LCA using a constant functional unit, it is proposed to allow use of a differing level of functionality in comparative LCA s to compensate for changes in user behaviour. For the comparative case of TV s, a larger LCD should be compared to a smaller CRT to cater for the change in consumers' perception of functionality. However, if the CRT is deemed not to be a suitable al ternative to $L C D$ due to the bulky size of the cabinet, a comparative LCA of CRT and LCD screens should not be performed as the result will no longer be meaningful.

\subsection{A new approach to LCA - Dynamic F unctional U nit D efinition}

In order to address the increasing functionality and changes in consumer usage behaviour due to new technologies, a new approach to defining the functional unit is needed. It is proposed to categorise the functions in a product into basic, performance and excitement features using K ano's model (see Table 1). The basic function is chosen as the anchoring of the functional unit definition since it is the primary function of the product that the customer sees as an essential need in purchasing the product. If a range of performance levels is available for the chosen basic function(s), then the performance level required by the consumer should be chosen for the functional unit definition. In the example of TVs, the basic function will be to display video content. However, this basic function can be fulfilled at different performance levels which can be measured in screen size (e.g. inches) since a range of sizes is available for both CRT and LCD. Hence, the performance feature can be considered in the specification of the functional unit by identifying the typical expected size (technical demand) for each of the compared technologies, potentially leading to different screen sizes being considered for CRT and LCD in the analysis.

Table 1 - Categorisation of product functionalities - examples

\begin{tabular}{|c|c|c|c|}
\hline Product & $\begin{array}{l}\text { Functional Demand } \\
\text { (Basic features) }\end{array}$ & $\begin{array}{l}\text { Technical Demand } \\
\text { (Performance features) }\end{array}$ & $\begin{array}{l}\text { Excitement } \\
\text { features }\end{array}$ \\
\hline \multirow{5}{*}{ TV } & \multirow{5}{*}{ Display video content } & Display size (inches) & \multirow{5}{*}{$\begin{array}{l}\text { Screen thickness } \\
\text { or depth }(\mathrm{mm})\end{array}$} \\
\hline & & Resolution (pixels) & \\
\hline & & Brightness $\left(\mathrm{cd} / \mathrm{m}^{2}\right)$ & \\
\hline & & Contrast ratio & \\
\hline & & Colour (number of colours) & \\
\hline Printer & Print & $\begin{array}{l}\text { Print speed (pages per minute), } \\
\text { Print resolution (dots per inch), } \\
\text { Colour reproduction }\end{array}$ & \multirow{3}{*}{$\mathrm{N} / \mathrm{A}$} \\
\hline Scanner & Scan & $\begin{array}{l}\text { Scanning resolution (dots per inch), } \\
\text { Scanning speed (pages per minute) }\end{array}$ & \\
\hline Copier & Copy & Copy speed (copies per minute) & \\
\hline
\end{tabular}


Copying resolution (dots per inch),

Over the course of time, competition can drive market expectations towards higher performance raising consumer expectations. For example, consumers have become aware of screen resolution in addition to viewing size since the introduction of high-definition TV broadcasting. Similar to the display size, a range of resolutions could also be offered which can influence consumer's expectation of TV functionality. When screen resolution becomes a performance feature for TV that influences purchasing behaviour, this must also be taken into account when determining the functional unit for the LCA study. As such, the technical demand for each function and also the multiple functionalities (and corresponding technical demands) in a product should be catered for as they get introduced into the product - as exemplified in Table 1 for different technologies. Contrary to ISO/TR 14049:2012 (ISO 2012) which states the functional unit should be defined either by one way $O R$ the other for multiple functions, the functional unit definition should incorporate the concept of AND by adding on the additional functions as they become necessary. This will prevent ignoring important aspects of usage behaviour that change over time.

\subsection{Addressing the influence of increase in functionality, integration and volume - manufacturer's perspective}

$M$ anufacturers typically introduce new technologies with the intention of improving existing functions while using less resource. From the user's perspective, this implies that the product can perform the same function at reduced operating cost and/or environmental impact or provide an increased functionality at the same cost/impact compared to previous product generations - the new product is more economically efficient and eco-efficient. $\mathrm{New}$ technologies also enable new product functions that were not possible previously and this can create new demand for additional functions. Thus, the user is influenced into using the product more, either because it costs less to operate or the user chooses to perform higher functional tasks rather than maintaining the previous level of functionality. This rebound effect (Sorrell 2009) may continue in a spiral fashion for continuously developing product generations and potentially offset the initial environmental impact reductions achieved. Also due to economies of scale, products become more and more accessible (financially) as prices get reduced, leading to higher volume sales and increased overall consumption ( $K$ im et al. 2014).

In order to be effective towards reduced impact from the manufacturer's total output, products need to be manufactured in a manner that accounts for changes in user behaviour as a result of functional changes leading to a requirement for:

- M ore efficient manufacturing processes that entail reduced cost and environmental impact of producing the product

- Reduced cost/environmental impact of operating the product for the given functionality to cater for the rebound effect as a result of increased functionality and the increase in total consumption due to higher volume sales as products become more accessible.

However, a difficulty in addressing the rebound effect of increasing functionality and volume is that particularly for the former, further increases in efficiency may boost the increase in consumption leading 
to higher levels of impact from the activity. A $n$ example is offered by the development of lighting technology over more than two centuries where the fraction of GDP (G ross Domestic Product) spend on lighting has remained remarkably constant around $0.5 \%$ in spite of efficiency improvements of several orders of magnitude for the lighting technologies from candles to LED lamps (T sao et al., 2010). This rebound effect represents a vicious circle, and a solution to manage such problems is needed - the strategy of increasing eco-efficiency does not automatically lead to eco-effectiveness - reducing the overall environmental impact of the manufacturer's output and the service that it offers to consumers (Hauschild, 2015). A s a starting point it is important to make this problem visible to the manufacturer, and here a possible approach could be to choose equivalent functionality when performing comparative LCA for different product technologies. For example, a product technology may offer function $f_{1}$, while a new technology may offer an improved function, $\mathrm{f}_{1^{\prime}}$ such that:

$$
f_{1} \leq f_{1}
$$

While $f_{1}$ and $f_{1^{\prime}}$ are not the same, a comparison may still be relevant if the two products are seen as valid alternatives for the consumer. LCA should thus be performed with a functional unit that respects any changes in the consumer's perception on functionality according to K ano's model, as discussed previously. The validity in performing a comparative LCA on products offering different functional levels should be confirmed by observing the changes in actual usage behaviour of the consumer. Also, if a new set of technologies allows the integration of a number of functions into a single product, LCA should be performed in comparison to the combination of single-function products that the new integrated product is replacing for the consumer. This approach to defining the functionality assumes that an integrated, multi-functional product with $\mathbf{n}$ functions may in practice replace $\mathbf{n}$ single-function products. In such a scenario, the assessor should consider whether comparison of equal or unequal functionality (performance level as discussed in Section 3.1) is representative of user behaviour as different technologies will enable different performance levels. For example, either the average functionality or the maximum/minimum performance level for the given functions $\left(f_{1}, f_{2} \ldots f_{n}\right)$ can be considered for analysis depending on the user behaviour. In the case of TV technologies, CRT TV s have a screen size range of 15-38 inches while LCD TV s have 11-50 inches (US EPA 2006). Thus, the user behaviour in the product choices should be reflected in defining the product functionality chosen for comparison. It should be noted that in certain circumstances, consumers may settle for less technical performance (functionality) for some functions if the product offers additional, integrated functions previously not available in one product. $\mathrm{H}$ ence, the basic functional requirement and corresponding technical requirement for each function that is numerically measureable should be specified to model a genuine functional al ternative for product comparison.

Table 2 - Functional/T echnical requirement

\begin{tabular}{clll}
\hline Function & $\begin{array}{l}\text { Functional } \\
\text { Requirement } \\
\text { (Basic) }\end{array}$ & $\begin{array}{l}\text { Technical } \\
\text { Requirement } \\
\text { (Performance) }\end{array}$ & Condition \\
\hline $\mathbf{1}$ & $\mathrm{x}$ & $a_{\text {Required }}$ (performance/unit measure) & $\mathrm{a}_{\text {specification }}$ e $a_{\text {Required }}$ \\
$\mathbf{2}$ & $y$ & $b_{\text {Required }}$ (performance/unit measure) & $b_{\text {Specification }}$ e $b_{\text {Required }}$ \\
$\mathbf{n}$ & $\mathrm{z}$ & $\mathrm{C}_{\text {Required }}$ (performance/unit measure) & $\mathrm{C}_{\text {Specificatione }} \mathrm{C}_{\text {Required }}$ \\
\hline
\end{tabular}


It should be noted that the assessor needs to ensure that the technical specification for each function is sufficient to meet the demand of the consumer as specified in Table $\mathbf{2}$ including consideration of whether any sacrifice in performance level is acceptable by the user for multi-functional products (i.e. users may be willing to sacrifice performance in exchange for integrated product functionality).

Once the correct level of functionality (reference point) is chosen for the comparison, the environmental analysis may also be extended to market volume level to assess the total environmental impact associated with the two alternative technologies. This could be done by simply comparing the total environmental footprint of the current technology and the projected volume of the alternative technology. This will inform the manufacturer of the environmental consequences of having the new technology replace the existing technology in the market ( $\mathrm{K}$ im et al. 2014). The information will allow the manufacturer to decide whether the eco-efficiency improvement with the new technology, i.e. the reduction in environmental impact at the level of the individual product, is sufficient to cater for a foreseen increase in market volume, and help the manufacturer avoid misleading conclusions regarding the contribution to a sustainable development from the planned change in the product. The same information can also assist stakeholders like consumers in their purchasing choices and aid decision-makers in developing the necessary policies for effective management and enforcement of sustainability measures.

By catering for changes in user behaviour as a result of functional and volume changes, LCA can better analyse the full environmental impact of product technology development and help in identifying the improvements that are needed for meeting the increasing demands in the market without increasing the resulting overall environmental impact.

\section{Case study of TV technology - CRT and LCD}

The use of the dynamic functional unit and the benchmarking of new product generations relative to the old one are illustrated by a case study on CRT and LCA TV s.

\subsection{F unctionality of TV}

\subsubsection{Basic feature}

Traditionally, the viewing size of the screen was a main factor influencing the purchasing decision of the user. So when comparative LCA was performed for TV s, screens of equal size were chosen for analysis (Socol of et al. 2005). This is only appropriate if screen size is the only basic feature expected by the user, but if the concept of dynamic functional unit is applied, the same size screen should not be compared. A ssuming that the consumer's perception of average size changed with the introduction of the new technology, the relevant CRT and LCD average size can be represented as the mean value;

$$
C R T_{\text {average }}=\frac{15+37}{2}=26.6 \quad L C D_{\text {average }}=\frac{12+60}{2}=36
$$

Therefore, comparison of 26.6 inch CRT and 36 inch LCD would then be more appropriate although they differ, in order to cater for higher functional expectation of the user to the LCD screen. 


\subsubsection{Performance feature}

Also, new technology has allowed for additional functionalities/improvements such as the following to be introduced into TV $\mathrm{s}$ :

- Screen resolution - High Definition TV broadcasting and LCDs leading to higher resolution images than CRT screens

- Energy consumption and efficiency - the evolution of LCD and LED technology has led to improved energy efficiency and with rising energy prices, consumers are becoming more aware of energy consumption of appliances and influencing product purchase decisions

For example, if the energy consumption of less than $100 \mathrm{~W}$ is taken into consideration as required performance feature, CRT2 and CRT3 do not meet this performance criterion. Thus, CRT1 should be compared with the LCD screen provided that the size difference ( $16 \mathrm{vs.} 21$ inches) is a fair comparison for the basic feature.

Table 3 - Features of TVs, and functional expectation (assumed selection) and alternative models

\begin{tabular}{|c|l|c|c|c|c|}
\hline & \multicolumn{1}{|c|}{ F eature Type } & Basic & Basic & Performance & Depth \\
\cline { 2 - 6 } & Measurement (variable) & $\begin{array}{c}\text { Size } \\
\text { (inches) }\end{array}$ & $\begin{array}{c}\text { Power } \\
\text { (W) }\end{array}$ & $\begin{array}{c}\text { R esolution } \\
\text { (Pixels) }\end{array}$ & $\begin{array}{c}\text { Size } \\
\text { (inches) }\end{array}$ \\
\hline & CRT 1 Samsung 765M B & 16 & 76 & $1600 \times 1200$ & 15.7 \\
\cline { 2 - 6 } & CRT2 Viewsonic E 90 & 18 & 100 & $1600 \times 1200$ & 18 \\
\cline { 2 - 6 } $\begin{array}{c}\text { Alternative } \\
\text { CRT and } \\
\text { LCD models }\end{array}$ & CRT3 Sony CPD-G 520 & 19.8 & 135 & $1600 \times 1200$ & 18.8 \\
\cline { 2 - 6 } & LCD Dell2001F P & 20.1 & 90 & $1600 \times 1200$ & 9.7 \\
\hline
\end{tabular}

\subsubsection{Excitement feature}

At times, new technologies offer breakthroughs that radically change the product functionality and central design features (A nderson and Tushman 1990). In the TV case, LCD technology has allowed the manufacture of much slimmer screen thickness than what is attainable with CRT screens. Although it does not directly contribute to the basic function of video display, it has completely changed the way TV $\mathrm{s}$ are placed and used around the home/office. If for example, consumers begin demanding screen depth of less than 10 inches as a basic feature of a TV screen, then the CRT models in Table 3 do not satisfy the requirement. The CRT technology can be said to have reached a technology limit as they are over 10 inches and only the LCD screen satisfies the requirement. Thus, if a comparative LCA based on screen thickness is needed, another alternative technology that can provide such function should be chosen such as a Plasma Display Panel (A oe et al. 2003). 


\subsection{Applying dynamic functional unit for TVs - manufacturer perspective}

When determining the functional unit and associated system boundary for an LCA that assesses the changes in overall environmental impact associated with the introduction of a new product model in the market, it is important to understand the actual usage behaviour and the consumer's expectations to functionality. LCA should be conducted based on the basic features expected by the consumer but it is important to note that due to new technologies - and the improvements they bring forth - the basic feature expected from a newer product may actually be higher than that of an old product. This means that what the consumer considers as basic features for the new product may actually be performance features for the old product generation, and manufacturers should take this into account when determining the functional unit. For the TV case, the features expected by the consumers should be identified and classified into basic, performance and excitement features to determine the functional unit that is relevant and applicable for both technologies (Table 3) and to decide whether the comparison is relevant at all from a user perspective.

A pplying the functional and technical demands based on the features assumed in Table 3, relevant CRT and LCD models can be chosen for comparison. Table 3 shows three different alternative models of CRT screens that can be chosen for comparison with the LCD screen. If CRT3 is chosen for comparison with the LCD screen as shown in Table 3, it can be observed that both offer comparable viewing size which will satisfy the basic functional demand. However, as energy consumption is also rated as a basic feature, the CRT 3 model cannot provide the lower energy consumption of the LCD model. Thus, to satisfy the user requirement to the energy consumption feature, an alternative product needs to be chosen.

The other two alternative CRT models in Table 3 (CRT1 and CRT2) offer an energy consumption which is closer to the LCD model but at the cost of reducing the functionality of viewing size. It is thus not possible for the two different TV technologies to offer both basic features at the same level, and this means that the assessor needs to make a conscious decision as to which product comparison best represents user preferences and purchase behaviour and determine whether any functional compromise on size is needed depending on this priority.

To assess the impact of total production volume, the assessor should use the functional unit that is now determined and apply at the volume level for the different product technologies. This methodology is presented in a previous article where four generations of A pple iPad $®$ models are compared with volume forecasting to demonstrate the expected increase due to market growth and/or sales effect of new product as it takes over the volume from the previous generation ( $\mathrm{Kim}$ et al. 2014). The same method can be applied to the different TV technologies and al so when comparing between manufacturers to understand how the volumes and the associated environmental impact may change. This will enable the assessor to choose the correct functional unit by taking into consideration the functional, behavioural and market volume changes when comparing different product technologies. 


\subsection{Discussion}

The proposed method of dynamic functional unit definition assessed the technical aspect of the product function but the following issues can also have an influence on the changing functionality of product. Offering a more adequate definition of functional unit for comparative studies of evolving technologies, it lends itself to both attributional and consequential LCAs, but in its nature it shares the consequential perspective by defining the dynamic functional unit based on an analysis of the likely consequences of the technological changes on the perception and behaviour of the user of the technology. In terms of decision contexts, the proposed approach to dynamic functional unit definition is relevant at the micro level for comparisons of eco-efficiencies of products applying different types or generations of technologies or incorporating multiple functionalities in one product. It is also relevant for the studies of technologies at a societal level or for a manufacturer's evaluation of the total environmental activity of the company in a tier 3 perspective comprising the whole product portfolio within a chosen consumption field or sector. The latter requires analysis of the size of the market and market share for the current technology and the corresponding values for the new technology. A number of challenges arise:

- How to determine the customer's trade-offs between different functional requirements - it is possible that different customers need or want different levels of performance and/or integration of multiple functions. This can be achieved through mass customisation (Coronado M ondragon and Coronado M ondragon 2011) as known from e.g. the automotive industry, where customisation of the product late in the manufacturing process allows combining the virtues of mass production and custom-made products. This allows consumer products to become different for each customer, and one functional unit definition may not be sufficient, depending on the functional difference introduced by the customisation.

- How to determine changes in consumption/market volumes for a new model which is not yet in the market - often unknown new technologies enter the market and render existing technologies obsolete but the requirement for efficiency improvement is unidentified for the new technology. This can lead to adverse environmental impact if the market shifts to new technology and manufacturers have no clear strategy and therefore study of different scenarios is needed.

- How to handle the situation where the market volume of a manufacturer grows not because of rebound effects but because the product outcompetes other products in the market (so the manufacturer's share of the total market grows)

Hence, changes in customer behaviour, technology change, market dynamics and competition should also be incorporated in the dynamic functional unit analysis for a holistic analysis. The latter point is particularly relevant when relating the environmental impact from the total output from a producer to science-based limits since the space available to the individual producer may be affected by market shares. Steffen and co-workers present planetary boundaries for man-made impact for a number of environmental processes that regulate the earth system and ensure a stable and benign environmental basis for our lives (Steffen et al., 2015). These boundaries constitute absolute limits for our loads on the environment, and in order to manage society so we stay below the boundaries, the pollution space that they define may be divided between societal actors at the level of countries, industrial sectors or even 
companies. In this way, absolute targets for environmental impact can be set for each of these actors to help ensure that they all contribute their share to keeping us within the safe operating space. The allocation between actors of the pollution space that is defined by the science-based targets is a matter of serious discussion (Bjørn and $\mathrm{H}$ auschild, 2015), but if it is based on value creation or fulfilment of societal or consumer needs an option might be to allocate each company a share of the space proportional to its share in the market.

\section{Conclusion}

This article presented the challenges of using a static, single functional unit definition in an industrial culture with constant evolution of products that influences usage behaviour. It was argued that the society is faced with the vicious circle of increased efficiencies that contribute to increased demand for consumption, a point which is not adequately addressed by current product LCA s. To gauge the overall trend in terms of environmental sustainability, a new approach to defining the functional unit was proposed to cater for changes in user behaviour building on the features put forwards in K ano's model of product functionalities. Using the proposed framew ork, the functional requirement for TV technologies was formulated and illustrated for a case with comparison of CRT and LCD based TV s. The case study showed that new features in LCD TV such as improved energy efficiency and reduced screen thickness lead to additional functional requirements from the market that may possibly influence user behaviour. However, using static, single functional unit definition fails to illustrate these changes and environmental impact assessment may not be a true representation of real life scenarios. Therefore, the framework for sustainability assessment of product development (functionality) is in need of further research to cater for functional, environmental and behaviour changes. To develop the proposed framework further, the product assessment should encompass the issues of improved product function, addition of new functions and changing consumer behaviour to determine the eco-efficiency and eco-effectiveness of manufacturers (such as the value-creation of companies, employment and the number of inhabitants from the global environmental space perspective). This may enable companies to relate their performance to absolute targets or limits like the planetary boundaries and provide a drive not only for improved efficiencies but a more eco-effective use of resources for future sustainability of society. In addition, the dynamic functional unit approach can give society a more holistic assessment of how products/functions are used, replaced and affect other products outside the company to gain a more comprehensive understanding of the environmental impact arising from product consumption.

\section{References}

A nderson P, Tushman M L (1990) Technological Discontinuities and D ominant Designs: A Cyclical Model of Technological Change. Adm Sci Q 35 (4):604-633

A oe T, M ichiyasu T, M atsuoka Y, Shikata N Case study for calculation of Factor X (E coEfficiency) - comparing CRT TV, PDP TV and LCD TV. In: Environmentally Conscious Design and Inverse M anufacturing, 3rd International Symposium on EcoD esign, Tokyo, Japan, 8-11 Dec 2003. pp 650-655 
Bjørn, A . and H auschild, M .Z.: Introducing carrying capacity based normalisation in LCA : framework and development of references at midpoint level. International J ournal of LCA , 20(7), 1005-1018, 2015.

Coronado M ondragon A E, Coronado M ondragon CE (2011) M anaging Technological Innovations Affecting Product Complexity, M odularity, and Supply Chain Structure. In: Fogliatto FS, da Silveira GJC (eds) M ass Customization. Springer Series in A dvanced $M$ anufacturing. Springer London, pp 87-104. doi:10.1007/978-1-84996-489-0_5

Hauschild M , J eswiet J, A Iting L (2005) From Life Cycle A ssessment to Sustainable Production: Status and Perspectives. CIRP A nn-M anuf Techn 54 (2):1-21

Hischier R, Reichart I (2003) M ultifunctional electronic media-traditional media. Int J Life Cycle A ssess 8(4):201-208

IPCC (2007) Climate Change 2007: A Synthesis Report A n A ssessment of the Intergovernmental Panel on Climate Change.

ISO (2006) Environmental management - Life cycle assessment - Principles and framework. ISO 14040. SA I Global,

ISO (2012) Environmental management - Life cycle assessment - Illustrative examples on how to apply ISO 14044 to goal and scope definition and inventory analysis. ISO/TR 14049:2012. SAI Global,

Kano N (1984) A ttractive quality and must-be quality. Hinshitsu (Quality) 14 (2):147-156

Kim SJ , K ara S Impact of Technology on Product L ife Cycle D esign: Functional and Environmental Perspective. In: Dornfeld DA, Linke BS (eds) 19th CIRP Conference on Life Cycle Engineering, U niversity of California at B erkeley, USA , 23-25 M ay 2012. Leveraging Technology for a Sustainable W orld. Springer, pp 191-196. doi:10.1007/978-3-642-29069-5

Kim SJ , Kara S, Kayis B (2014) A nalysis of the impact of technology changes on the economic and environmental influence of product life-cycle design. Int J Computer Integr M anuf 27 (5):422-433. doi:10.1080/0951192X .2013.814161

M atheys J, A utenboer W , Timmermans J - M , M ierlo J, B ossche P, M aggetto $G$ (2007) Influence of functional unit on the life cycle assessment of traction batteries. Int J LCA 12 (3):191-196. doi:10.1065/lca2007.04.322

Socolof M L, Overly JG, Geibig JR (2005) Environmental life-cycle impacts of CRT and LCD desktop computer displays. J Clean Prod 13 (13-14):1281-1294. doi:10.1016/j.jclepro.2005.05.014

Sorrell S (2009) J evons' Paradox revisited: The evidence for backfire from improved energy efficiency. Energy Policy 37 (4):1456-1469. doi:10.1016/j.enpol.2008.12.003

Steffen W, Richardson K, Rockström J et al. (2015) Planetary boundaries: Guiding human development on a changing planet. Science 347(6223), 736-746

US EPA (2006) Preliminary Television M arket and Industry Research Prepared for: US EPA in support of the ENERGY STAR ${ }^{\circ}$ TV Specification Revision US EPA.

Tsao JY, Saunders HD, Creighton JR, Coltrin M E, Simmons J A (2010) Solid-state lighting: an energy-economics perspective. J. Phys.D: A ppl. Phys. 43, 354001 (17p) 
